\title{
Erzurum ve çevre illerde psödotümör serebri tanısı ile takip edilen hastaların klinik ve demografik verileri
}

\section{Clinical and demographic data of patients followed up with the diagnosis of pseudotumor cerebri in Erzurum and environmental provinces}

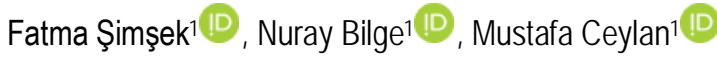 \\ ${ }_{1}$ Atatürk Üniversitesi Tıp Fakültesi, Nöroloji Anabilimdalı, Erzurum/Türkiye
}

\section{Öz.}

Amaç: Psödotümör serebri kafa içi basınç artışı ile karakterize olan ve doğurganlık çağındaki kadınlarda sık görülen bir hastalıktır. Çalışmamızda Türkiye'nin doğusunda yaşayan Erzurum ve çevre illerden gelen psödotümör serebri hastalarının klinik ve demografik özelliklerinin araştırılması amaçlanmıştır.

Materyal ve Metot: Çalışmamızda Ocak 2015-Aralık 2018 tarihleri arasında Atatürk Üniversitesi Nöroloji kliniğinde psödotümör serebri tanısı ile takip edilen Erzurum ve çevre illerden gelen 27 hastanın kayıtları retrospektif olarak tarandı. Hastaların tanısı modifiye Dandy kriteleri ile konuldu.

Bulgular: Hastaların 23' ü $(\% 85,18)$ kadın, 4'ü $(\% 14,81)$ erkekti. Yaş ortalaması kadınlarda 38,75, erkeklerde 48,25 idi. $17(\% 62,96)$ hastada baş ağrısı, 14 (\%51,85) hastada bulanık görme, 4 (\%14,81) hastada çift görme, $5(\% 18,51)$ hastada bulantı-kusma, $3(\% 11,11)$ hastada kulak çınlaması vardı. Göz dibi muayenesinde 3 $(\% 11,11)$ hastada tek taraflı, $24(\% 88,88)$ hastada bilateral papil ödem izlenmişti. BOS basınç ölçümü ortalaması $348,33 \mathrm{mmH}_{2} \mathrm{O}$ idi. Manyetik rezonans venografide $5(\% 18,51)$ hastada transvers sinüste tek taraflı hipoplazi izlenmişti. Manyetik rezonans görüntüleme incelemelerinde \%62,96 $(n=17)$ ile perioptik subaraknoid boşluğun genişlemesi en sık görülen bulguydu. Etiyolojik neden olarak 8 hastada obesite, 3 hastada ilaç kullanım öyküsü tesbit edilirken 16 hastada etiyoloji saptanamadı.

Sonuç: Hastalarda en sık görülen semptom baş ağrısı ve en sık muayene bulgusu papil ödemdir. Nörogörüntülemede parankimal veya meningeal patoloji olmayıp tanıyı destekleyici bulgular izlenir. Hastalığın en önemli komplikasyonu görme kaybı olduğundan erken tanı vizüel fonksiyonları korumak için önemlidir.

Anahtar kelimeler: Psödotümör serebri, Baş ağrısı, Papil ödem, Lomber ponksiyon

\section{Abstract}

Background: Pseudotumor cerebri is a common disease in reproductive-age women characterized by increased intracranial pressure. The aim of our study was to investigate the clinical and demographic characteristics of pseudotumor cerebri patients from Erzurum and nearby provinces living in eastern Turkey.

Methods: In our study, the records of 27 patients from Erzurum and nearby provinces, followed-up with the diagnosis of pseudotumor cerebri at the Ataturk University, Neurology Outpatient Clinic between January 2015 and December 2018, were retrospectively reviewed. The diagnosis of the patients was made with modified Dandy criteria.

Results: Of the patients, $23(85.18 \%)$ were female and 4 (14.81\%) were male. The mean age was 38.75 in females and 48.25 in males. Of the patients, $17(62.96 \%)$ had headache, $14(51.85 \%)$ had blurred vision, 4 $(14.81 \%)$ had double vision, $5(18.51 \%)$ had nausea and vomiting, $3(11.11 \%)$ had tinnitus. Fundus examination revealed unilateral papilledema in $3(11.11 \%)$ patients and bilateral papilledema in $24(88.88 \%)$ patients. The mean CSF pressure measurement was $348.33 \mathrm{mmH} 2 \mathrm{O}$. Magnetic resonance venography showed unilateral hypoplasia of the transverse sinus in 5 (18.51\%) patients. Distention of the perioptic subarachnoid space was the most common finding on Magnetic resonance Imaging examinations with $62.96 \%$ $(n=17)$. Obesity and history of drug use were found to be the etiological causes in 8 and 3 patients, respectively, while the etiology could not be determined in 16 patients.

Conclusion: The most common symptom is headache and findings is papillary edema in patients. Neuroimaging does not show parenchymal or meningeal pathology, but findings that support the diagnosis are observed. Since the most important complication of the disease is loss of vision, early diagnosis is important to maintain visual functions.

Key words: Pseudotumor cerebri, Headache, Papilledema, Lumbar puncture

\section{Sorumlu Yazar I \\ Corresponding Author}

Dr. Fatma Şimşek

Atatürk Üniversitesi Tıp Fakültesi Nöroloji Anabilimdalı, Erzurum/Türkiye

Tel: +90 (505) 8347780

e-mail: klamaks@hotmail.com

Geliş tarihi / Received: 23/02/2019

Kabul tarihi / Accepted: 15/05/2019

DOI: $10.35440 /$ hutfd. 531383 


\section{Giriş}

Psödotümör serebri (PTS) ilk olarak Quincke (1) tarafından tanımlanmış olup doğurganlık çağındaki kilolu kadınlarda sık görülen, artmış kafa içi basıncı ile karakterize bir hastalıktır. PTS yerine idiopatik intrakraniyal hipertansiyon (iiH) terimi de kullanılmaktadır.

PTS insidansı genel nüfusta yılda 0,5-2/100.000 iken, obez ve doğurganlık çağındaki kadınlarda yılda 12-20/100.000' dir (2). Kilo artışı ile insidansında belirgin artış izlenmektedir.

PTS' nin patogenezi belirsiz olup beyin omurilik SIVISI (BOS) aşırı üretimi, BOS akışında obstrüksiyon ve venöz sinüs basıncında artış şeklinde ileri sürülen üç mekanizma vardır (2-4). Hastalardaki en sık klinik prezentasyon baş ağrısıdır $(5,6)$. Baş ağrısı, migrenöz karakterli, gerilim tipi şeklinde veya diğer baş ağrısı tiplerini taklit edebilir. Hastalarda baş ağrısı dışında sık görülen semptomlar arasında diplopi, bulantı, boyun ağrısı ve sırt ağrısı sayılabilir $(7,8)$. Nörolojik muayenede intrakranial basınç artışına bağlı altıncı kranial sinir paralizisi ve optik disk ödemi tesbit edilebilir. Optik disk ödemi iskemik olaylarda da izlenebilmekte olup PTS'ye spesifik bir bulgu değildir.

Hastaların takibinde görme alanı testi kullanımaktadır. Görme alanı testi en kullanışlı, ölçülebilir görsel fonksiyon testidir. En yaygın görme alanı defektleri lokalize sinir lifi demeti defekti (\% 60), daha sıklıkla genişlemiş kör nokta şeklinde izlenmiştir. Inferior yarım görme kaybı, superior yarım görme kaybından daha fazla izlenmiştir $(5,6,9)$. Son dönemlerde papil ödemi nesnel olarak değerlendirmek için optik koherans tomografi (OCT) kullanılmaktadır.

Tanı konulurken nörogörüntüleme gerekli olup çekilen manyetik rezonans görüntülemede beyin parankiminin normal olduğu görülmelidir. Lateral dekübit pozisyonda yapılan lomber ponksiyonda (LP) yetişkin ve ileri yaşta 250 $\mathrm{mmH}_{2} \mathrm{O}$, çocuk ve adelösanlarda açıış BOS basıncının $280 \mathrm{mmH}_{2} \mathrm{O}$ üzerinde ve BOS bileşenlerinin normal olması tanısaldır $(10,11)$. Tanıda Modifiye Dandy kriterleri kullanılmaktadır (Tablo 1).

Tedavide amaç baş ağrısı semptomlarını ve görsel şikayetleri düzeltmeye yönelik olup tedavide standardizasyon bulunmamaktadır. Hastalık tedavi edilmezse progresif görme kaybı ve optik atrofiye neden olabilir (12). Kalıcı görme kaybına neden olabildiği için tanı ve tedavisi aciliyet gerektirir.

Bu çalışmada bölgemizde PTS olarak takip ettiğimiz 27 hastanın etiyolojileri, yaş ve cinsiyet dağılımı, semptomları, muayene bulguları, manyetik rezonans görüntüleme (MRG) bulguları ve tedavileri tartışımıştır. Çalışma için kurumumuzun 01 sayı, 41 karar nosu ile 13.02.2019 tarihinde etik kurul onayı alınmıştır.

\section{Materyal ve Metod}

Çalışmamızda Ocak 2015-Aralık 2018 tarihleri arasında Atatürk Üniversitesi Nöroloji kliniğinde PTS tanısı ile takip edilen Erzurum ve çevre illerden gelen 27 hastanın kayıtları retrospektif olarak tarandı. Her hastanın yaş, cinsiyet, nörolojik muayeneleri, ayrıntılı göz muayene bulguları, MRG ve MR venografileri, BOS parametreleri, tedavi protokolleri incelendi. Hastaların tanılarında Modifiye Dandy kriterleri kullanıldı. Hastaların MRG ve MR venografi görüntüleri hastane bilgi yönetim sistemi kullanılarak yeniden değerlendirildi. MRG de parankim tutulumu izlenen hastalar, malign hipertansyon nedeniyle çoklu antihipertansif kullanımı olanlar ve yakın zamanlı yapılan göz operasyonu sonrası şikayeti gelişen hastalar çalışmaya alınmadı.

\section{Tablo 1. Modifiye Dandy kriterleri}
a. Papilödem
b. Normal nörolojik muayene bulguları - kraniyal sinir anor- mallikleri hariç
c. Normal nörogörüntüleme: Hidrosefali, kitle, yapısal lezyon ve anormal meningeal tutulum olmamalı
d. Normal BOS kompozisyonu
e. Uygun şekilde yapılmış lomber ponksiyonda BOS açılış ba- sıncının yüksek olması ( $\geq 250 \mathrm{mmH} 20$ )

\section{BOS: Beyin omurilik SIVISI}

\section{Bulgular}

Ocak 2015-Aralık 2018 tarihleri arasında Atatürk Üniversitesi Nöroloji kliniğinde PTS tanısı ile takip edilen 27 hastanın kayıtları retrospektif olarak incelendi. Hastaların 23' ü $(\% 85,18)$ kadın, 4'ü $(\% 14,81)$ erkekti. Hasta grubumuz 18 yaş üstünde olup yaş ortalaması kadınlarda 38,75 , erkeklerde 48,25 idi. Bayan hastaların 8'inde vücut kitle indeksi $30 \mathrm{~kg} / \mathrm{m}^{2}$ üzerinde olup obesite izlenirken, erkek hastaların vücut kitle indeksi normaldi. Hastalarda görülen semptomlara bakıldığında $17(\% 62,96)$ hastada baş ağrısı, 14 $(\% 51,85)$ hastada bulanık görme, $4(\% 14,81)$ hastada çift görme, $5(\% 18,51)$ hastada bulanti-kusma, $3(\% 11,11)$ hastada kulak çınlaması vardı. Çift görme şikayeti dört hastada olup nörolojik muayenede bir hastada altıncı kranial sinir paralizisi izlenirken diğer hastaların nörolojik muayeneleri normaldi. Göz dibi muayenesinde $3(\% 11,11)$ hastada tek taraflı, $24(\% 88,88)$ hastada bilateral papil ödem izlenmişti. Hastaların klinik, nörolojik ve fundoskopik bulguları tablo 2 de özetlenmiştir. Hastaların hepsinde kranial MR görüntülemeleri normaldi. MR venografide $5(\% 18,51)$ hastada transvers sinüste tek taraflı hipoplazi izlenmişti. Lateral dekübit pozisyonda yapılan LP sonrası BOS basıncı bir hastada normal sınırlarda, beş hastada gri zon olarak adlandırılan $200-250 \mathrm{mmH}_{2} \mathrm{O}$ arasında, 21 hastada $250 \mathrm{mmH}_{2} \mathrm{O}$ üzerindeydi. BOS basınç ölçümü ortalaması $348,33 \mathrm{mmH}_{2} \mathrm{O}$, tüm hastaların BOS mikroskobik ve biyokimyasal özellikleri normaldi. BOS basıncı normal olan bir hastanın muayenesinde bilateral papil ödem, MRG' sinde perioptik subaraknoid boşlukta genişleme, optik sinirde tortiozite, boş sella ve posterior globda düzleşme vardı. MRG incelemelerinde $\% 62,96(n=17)$ perioptik subaraknoid boşluğun genişlemesi, \% 59,25 ( $n=16)$ boş sella, \% 37,03 
( $n=10)$ optik sinir kul finda tortiozite, , $\% 7,40(n=2)$ posterior globda düzleşme, \% 22,22 ( $n=6$ ) hastada normal MRG bulguları izlendi. MRG' de 10 hastada boş sella, perioptik subaraknoid boşluğun genişlemesi, optik tortiozite birlikteliği vardı. Görme alanı testinde dokuz hastada kör noktada genişleme, 16 hastada periferik görme alanında daralma ve iki hastada görme alanı testinin normal olduğu izlenmişti. Etiyolojik neden olarak sekiz hastada obesite, üç hastada ilaç kullanımı tesbit edilirken 16 hastada etiyoloji saptanamadı. İlaca sekonder gelişen PTS'lerde BOS basıncı 500 $\mathrm{mmH}_{2} \mathrm{O}$ üzerindeydi. Etiyolojide ilaç kullanımı olan hastalara bakıldığında bir kişide lösemi nedeni ile all-trans retinoik asit kullanımı, bir kişide prostat kanseri nedeni ile leuprolid kullanımı, bir kişide astım nedeni ile budesonid kullanımı vardı. 21 hastanın tedavisinde asetozolamid monoterapisi, altı hastanın tedavisinde asetozolamid ve topiramat şeklinde politerapi kullanılmıştı.

Tablo 2. Hastaların klinik, nörolojik ve fundoskopik bulguları

\begin{tabular}{lcc}
\hline Klinik bulgular & Hasta sayısı (n) & $\%$ \\
$\quad$ Başağıısı & 17 & 62,96 \\
$\quad$ Bulanık görme & 14 & 51,85 \\
$\quad$ Tinnitus & 3 & 11,11 \\
$\quad$ Bulantı-kusma & 5 & 18,51 \\
$\quad$ Diplopi & 4 & 14,81 \\
Nörolojik muayene bulguları & & \\
$\quad$ 6. kranial sinir paralizisi & 1 & 3,70 \\
Fundoskopik bulgular & & \\
$\quad$ Bilateral papil ödem & 24 & 88,88 \\
Tek taraflı papil ödem & 3 & 11,11 \\
& & \\
\end{tabular}

\section{Tartışma}

Hastalarımızın cinsiyet dağılımına baktığımızda \% 85,18'i kadın, \% 14,81'i i rkekti. Yaş ortalamamız 40,18, en sık görülen semptom \% 62,96 ile baş ağrısıydı. Obesite oranımız \% 29,62 idi. Dört hastamızda çift görme şikayeti olup bir kişide altıncı kranial sinir paralizisi vardı. En sık görülen MRG bulgusu \% 62,96 ile perioptik subaraknoid boşluğun genişlemesiydi. Görme alanı testinde \% 59,25 periferik görme alanında daralma, \% 33,33 kör noktada genişleme, $\% 7,40$ oranında görme alanı normalliği izlenmişti.

Pediatrik (13) ve yetişkin (14) hastaların \% 63-98' inde görülen baş ağrısı PTS'nin en yaygın semptomudur. Insidansı obes ve doğurganlık çağındaki kadınlarda, genel nüfusa göre çok daha fazladır (2). Literatürde ortalama tanı yaşı 25-36 yıl olarak bildirilmiştir (2). Hastalarımızda yaş ortalaması 40,18 olup literatürle benzerdi.

PTS tanısı ile takip ettiğimiz hasta grubunda obesite oranı $\% 29,62$ idi. Obesite ile PTS insidansının arttığı bilinmektedir. Vücut ağırlığının \%6 oranında azalmasının görsel fonksiyonlarda ve papil ödemde iyileşme ile ilgili olduğunu gösteren kanıtlar vardır (15). PTS tanılı obesite problemi olan hastalarda medikal tedaviye eş zamanlı olarak diyet programı düzenlenmesi klinik iyileşmeye katkı sağlayan nonmedikal bir destek tedavisidir.

Etyolojiye yönelik incelemede sekiz hastada obesite, üç hastada ilaç kullanımı tesbit edilmişti, 16 hasta ise idiyopatik gruptaydı. 26 hasta modifiye Dandy kriterlerine göre PTS tanısı almıştı. Görsel şikayetler ile takip edilen bir hastada bilateral papil ödem, nörolojik muayene normal, MR venografi normal, MRG'de perioptik subaraknoid mesafede genişleme, optik sinirde tortiozite, posterior globda düzleşme ve boş sella izlenmiş ancak BOS basıncı 160 $\mathrm{mmH}_{2} \mathrm{O}$ olarak normal sınırlarda ölçülmüştü. BOS biyokimyasal ve mikrobiyolojik incelemesi normaldi. Görme alanı testinde periferik görme alanında daralma olan ve mevcut durumunu açıklayacak oftalmolojik patoloji bulunmayan hasta olası PTS olarak kabul edilip asetozolamid tedavisi başlanmış ve görme alanı testi ile takip edilmişti. Görme alanı testinde bilateral periferik görme alanında daralma izlenen hastanın altı aylık takip sonrası kontrol göz muayenesinde papil ödem de ve görme alanı testinde bir önceki bulgulara göre düzelme tesbit edilmişti. Hastanın OCT çekimi olmadığı için papil ödemdeki düzelme nesnel olarak değerlendirilememiştir. Hastanın iki yıllık takip sonrası göz muayenesinde optik diskte hafif siliklik izlenmiş ve görsel şikayetleri büyük oranda düzelmişti. Görme alanı testinde bilateral üst dış kadranda minimal daralma izlenmişti, birinci yılında yapılan tekrar LP'de BOS basıncı yine normal sınırlarda ölçülmüştü. Hastanın MRG bulguları, göz muayenesi ve mevcut tablosunu açıklayacak başka bir patolojinin olmaması PTS tanısını desteklerken BOS basıncının normal olması tanı kriterlerini karşılamamaktaydı. $\mathrm{Bu}$ durum BOS basıncı normal PTS vakaları olabileceği intimalini düşündürmektedir.

Hastalarımızda baş ağrısı dışında $14(\% 51,85)$ hastada bulanık görme, $4(\% 14,81)$ hastada çift görme, $5(\% 18,51)$ hastada bulantı-kusma, $3(\% 11,11)$ hastada kulak çınlaması vardı. Pulsatil tinnitus, genellikle boğucu bir ses veya kalp atışı olarak tanımlanır ve hastaların\% 60 'ında ortaya çıkabilir $(6,8)$. Çalışmamızda tinnitus görülme oranı $\% 11,11$ olup literatüre göre belirgin düşüktü. Bunun sebebinin kulak çınlaması şikayetini direk bildiren hastaların kayıtları alıırken sorgulamada diğer hastalara kulak çınlaması şikayetinin sorulmamasından ve hastalarında bunu önemsemeyerek bildirmediklerinden kaynaklanıyor olabileceğini düşündük.

Görme alanı testinde \%33,33 ( $n=9)$ kör noktada genişleme, $\% 59,25(n=16)$ periferik görme alanında daralma ve $\% 7,40$ (n=2) görme alanı testinin normal olduğu izlenmişti. Wall ve George (16) yaptıkları çalışmada en sık görülen görme alanı defektleri olarak kör noktada genişleme, nazal defektler ve generalize depresyon tesbit etmişlerdir. Hasta grubumuzda en sık görülen görme alanı defekti $\% 59,25$ ile periferik görme alanında daralma yani generalize depresyondu. Literatürde en sık görülen görme alanı defekti kör 
noktada genişleme iken bizde periferik görme alanında daralma olmasının nedeninin ülkemizde hastaların şikayetler daha belirgin hale gelince yani daha geç dönemde doktor başvurularının yapılmış olmasından kaynaklanıyor olabileceğini düşündürmektedir. Papil ödem genellikle bilateral ve simetrik görülmekle birlikte, hafif simetrik veya \%10 oranında unilateral olabilir (17). Çalışmamızda literatürle uyumluydu ve 27 hastanın 3'ünde $(\% 11,11)$ unilateral, 24'ünde bilateral papil ödem vardı. Hastaların tedavi sonrası görme alanı testi ve göz muayenelerinde kademeli olarak düzelme izlenmiști.

Hastalara tedavi amaçlı ön planda asetozolamid başlanmış ve takibinde $1500 \mathrm{mg} /$ gün dozuna çıkılmasına rağmen klinik olarak iyileşme izlenmeyen 6 hastanın tedavisine topiramat eklenerek $100 \mathrm{mg} / \mathrm{gün}$ dozuna çıkımıştı. 21 hasta tedavisine asetozolamid monoterapisi ile devam etmişti. Hastaların ilaç kullanım süreleri birbirinden farklı olup 2 yıl sonrasında şikayetleri düzeldiği için tedavisi sonlandırılan hastaların yanında tedavi kesildikten sonra şikayeti yinelediği için ilaç alımına halen devam eden hastalar vardı. Tanı anında sekonder neden tesbit ettiğimiz ilaca bağlı PTS gelişen 3 vaka kullandıkları ilaçlar kesilip asetozolamid verilince 6 ayda tama yakın düzelmişti. Buda sekonder nedene bağlı gelişen PTS lerde basınç ne kadar yüksek olursa olsun idiyopatik gruba göre tedaviye yanıtın ve klinik düzelmenin daha iyi olduğunu göstermektedir. PTS tedavisinde ilaç dozu ve kullanım süresi ile ilgili standardizasyon bulunmamaktadır. Ilaç tedavisinden fayda görmeyen hastalarda görme kaybı oluşumunu engelleyebilmek adına medikal tedavinin yetersiz geldiği noktada cerrahi seçenekler açısından değerlendirme yapılmalıdır. Tedavide steroidlerin yeri tartışmalı olup steroidlerin yan etki olarak kilo artışına neden olması, kilo artışının PTS de risk faktörü olması nedeni ile ve diğer sistemik yan etkilerinden dolayı uzun süre kullanımları önerilmemektedir. Şiddetli görme kaybı olan hastalarda akut dönemde kısa süreli kullanımının önerildiği birkaç çalışma olup uzun süreli kullanımdan kaçınılmalıdır $(18,19)$. Tedavide diğer bir seçenek LP olup bunun kullanımı da sınırıdır. Küçük vaka serilerinde hızlı ilerleyen görme kaybı ile gelen fulminan vakalarda veya gebelik nedeni ile ilaç kullanamayan $\mathrm{IiH}$ tanılı hastalarda geçici tedavi olarak yararlı olabileceği belirtilmiştir $(20,21)$. Boşaltılan BOS miktarının kısa sürede tekrar üretilerek BOS basıncını eski düzeyine ulaştırması nedeni ile uzun vadeli tedavide etkinliği olmadığı düşünülmektedir.

Çalışmamız cinsiyet, en sık görülen semptom ve eşlik eden diğer semptomlar yönüyle literatürle benzer sonuçlara sahipti. Tinnitus oranımız literatürden daha düşük, görme alanı testinde literatürde en sık kör noktada genişleme izlenirken çalışmamızda en sık periferik görme alanında daralma izlenmişti. Çalışmamızda 26 hasta Dandy kriterlerini karşılarken 1 hastamız BOS basıncının normal olması nedeni ile kriterleri tam karşılamıyordu. Hastamızda olduğu gibi BOS basıncı normal olup PTS nin diğer tanı kritelerini karşılayan hastalar tedaviye olumlu cevap veriyorsa olası PTS olarak değerlendirilebilecekleri kanaatindeyiz. Çalışmamızda olduğu gibi ilaca sekonder gelişen PTS lerde klinik düzelmenin daha hızlı olduğunu idiyopatik olanlarda daha uzun soluklu tedavi gerektiğini görmekteyiz. Çalışmamızda ilaca sekonder PTS'lerde BOS basıncı daha yüksek iken klinik düzelmenin daha hızlı ve erken olması PTS'de BOS basınç yüksekliği değil etiyolojik nedenin klinik tabloya yön verdiğini göstermektedir. Bu nedenle hastalarda tanı anında sekonder nedenlerin iyi araştıııması önem arzetmektedir.

Sonuç olarak baş ağrısı kliniği ile gelen ve nörolojik muayenede papil ödem tesbit edilen hastalarda nörogörüntülemenin normal olması durumunda PTS açısından BOS basınç ölçümü yapılmalıdır. Hastalardaki majör komplikasyon görme kaybı olduğundan vizüel fonksiyonların korunabilmesi için erken tanı önemlidir. İlaç tedavisine yanıt vermeyen hastalarda cerrahi tedavi seçenekleri değerlendirilmelidir.

\section{Kaynaklar}

1. Quincke H. Uber meningitis serosa: Sammlung Klinische Vortrage 67. Inn Med 23. 1893:655-694.

2. Markey KA, Mollan SP, Jensen RH, Sinclair AJ. Understanding idiopathic intracranial hypertension: mechanisms, management and future directions. The Lancet Neurol 2016; 15(1):78-91.

3. Mollan SP, Ali F, Hassan-Smith G, Botfield, H, Friedman DI, Sinclair AJ. Evolving evidence in adult idiopathic intracranial hypertension: pathophysiology and management. J Neurol Neurosurg Psychiatry 2016; 87(9):982-992.

4. Orefice G, Celentano L, Scaglione M, Davoli M, Striano S. Radioisotopic cisternography in benign intracranial hypertension of young obese women. A seven-case study and pathogenetic suggestions. Acta Neurol (Napoli) 1992; 14(1):39-50.

5. Smith SV, Friedman DI. The idiopathic intracranial hypertension treatment trial: a review of the outcomes. Headache 2017; 57(8):1303-1310.

6. Wall M, Kupersmith MJ, Kieburtz KD, Corbett JJ, Feldon SE, Friedman $\mathrm{DI}$, et all. The idiopathic intracranial hypertension treatment trial: clinical profile at baseline. JAMA Neurol 2014; 71(6): 693-701.

7. Headache Classification Committee of the International Headache Society (IHS) The International Classification of Headache Disorders, (beta version). Cephalalgia 2013;33(9):629-808.

8. Giuseffi V, Wall M, Siegel PZ, Rojas PB. Symptoms and disease associations in idiopathic intracranial hypertension (pseudotumor cerebri): a case-control study. Neurology 1991;41(2 part 1):239244.

9. Keltner JL, Johnson CA, Cello KE, Wall M. Baseline visual field findings in the Idiopathic Intracranial Hypertension Treatment Trial (IIHTT). Invest Ophthalmol Vis Sci 2014; 55(5):3200-3207.

10. Friedman DI, Liu G, Digre KB. Diagnostic criteria for the pseudotumor cerebri syndrome in adults and children. Neurology 2013; 81(13):1159-1165.

11. Friedman DI. The pseudotumor cerebri syndrome. Neurologic Clinics 2014; 32(2): 363-396.

12. Corbett JJ, Savino PJ, Thompson HS, Kansu T, Schatz NJ, Orr LS, et all. Visual loss in pseudotumor cerebri. Follow-up of 57 patients from five to 41 years and a profile of 14 patients with permanent severe visual loss. Arch Neurol. 1982;39(8):461-474.

13. Aylward SC, Aronowitz C, Roach ES. Intracranial hypertension without papilledema in children. J Child Neurol 2016;31(2):177- 
183.

14. Wall M. The headache profile of idiopathic intracranial hypertension. Cephalalgia 1990;10(6):331-335.

15. Kupersmith MJ, Gamell L, Turbin R, Peck V, Spiegel P, Wall M. Effects of weight loss on the course of idiopathic intracranial hypertension in women. Neurology 1998;50(4):1094-1098.

16. Wall $\mathrm{M}$, George D. Idiopathic intracranial hypertension. A prospective study of 50 patients. Brain 1991; 114(1):155-180.

17. Almarzouqi SJ, Morgan ML, Lee AG. Idiopathic intracranial hypertension in the Middle East: A growing concern. Saudi J Ophthalmol 2015;29(1):26-31.

18. Cleves-Bayon C. Idiopathic intracranial hypertension in children and adolescents: an update. Headache J Head Face Pain. 2017;58(3): 485-93.

19. Portelli M, Papageorgiou P. An update on idiopathic intracranial hypertension. Acta Neurochir. 2016;159(3):491-9.

20. Thambisetty M, Lavin $P$, Newman $N$, Biousse V. Fulminant idiopathic intracranial hypertension. Neurology. 2007;68(3):229-32.

21. Huna-Baron $R$, Kupersmith $M$. Idiopathic intracranial hypertension in pregnancy. J Neurol. 2002;249(8):1078-81. 